\title{
ANÁLISE DAS MANIFESTAÇÕES PATOLÓGICAS EM EDIFICAÇÕES HISTÓRICAS: UM ESTUDO DE CASO NAS FACHADAS DO CONJUNTO URBANO DA PRAÇA XV DE NOVEMBRO EM FLORIANÓPOLIS - SC.
}

\author{
REICHERT, SABRINA \\ Engenheira Civil \\ Faculdade Unisociesc \\ Santa Catarina; Brasil \\ reichert.sr@outlook.com
}

\author{
LIVI, CAROLINA NODA \\ Professora \\ Faculdade Unisociesc \\ Santa Catarina; Brasil \\ carolina.livi@unisociesc.com.br
}

\section{RESUMO}

A preservação do patrimônio histórico é uma ação de fundamental importância para a perpetuação da cultura e identidade das cidades. Neste contexto, o presente artigo apresenta a análise de um estudo de caso realizado em edificações históricas localizadas na cidade de Florianópolis, Santa Catarina. Foram selecionadas quatro edificações no complexo construído entre os séculos XVIII e XIX, em diferentes estágios de deterioração, para uma avaliação qualitativa das manifestações patológicas presentes nas fachadas. A metodologia para obtenção do diagnóstico e proposição de intervenção contempla o levantamento de registros históricos relacionados à construção, manutenção e sinistros; identificação, mapeamento e inspeção visual dos sintomas e dos agentes atuantes. Com isso, apresenta-se sugestões de tratamento, respeitando-se as características arquitetônicas originais. Destaca-se que a principal contribuição deste artigo é evidenciar a importância da atuação dos profissionais de Engenharia Civil na elaboração de planos estratégicos e projetos eficientes para restauração e preservação histórica do patrimônio municipal, uma área que, por vezes, é pouco discutida no cenário local. Palavras-chave: Manifestações Patológicas; Edificações Históricas, Patrimônio Material; Preservação; Fachadas.

\section{ABSTRACT}

The preservation of the historical heritage is an action of fundamental importance for the perpetuation of the culture and identity of the cities. In this context, the present article shows the analysis of a case study carried out in historical buildings located in the city of Florianopolis, Santa Catarina. Four buildings were selected in the complex built between the eighteenth and nineteenth centuries, in different stages of deterioration, for a qualitative evaluation of the pathological manifestations present in the facades. The methodology for obtaining the diagnosis and proposition of intervention includes a survey of historical records related to the construction, maintenance and claims; identification, mapping and visual inspection of the symptoms and acting agents. With this, suggestions of treatment are introduced, respecting the original architectural characteristics. It is noteworthy that the main contribution of this article is to highlight the importance of the work of Civil Engineering professionals in the elaboration of strategic plans and efficient projects for restoration and historical preservation of the municipal heritage, an area that is sometimes little discussed in the local scenario.

Keywords: Pathological Manifestations; Historical Buildings; Material Heritage; Preservation; Facades.

\section{INTRODUÇÃO}

A área da Engenharia Civil tem diversas áreas e estuda a concepção, os projetos e a execução das estruturas e infraestruturas. Aos profissionais cabem garantir a vistoria, o diagnóstico e a manutenção necessária para a preservação das estruturas em estudo. Dentro deste contexto, uma das facetas que recebe destaque é a das Patologias das Construções. Isso porque apresentam perda de desempenho seja pelo desgaste natural, pela ocorrência de acidentes/sinistros, ou pela falta de manutenção adequada. Tal cenário torna-se crítico quando se trata de edificações históricas, em que leva-se em consideração aspectos de reparo e restauro, respeitando-se as características originais, materiais utilizados, entre outros.(OLIVARI, 2003)

Sendo assim, este estudo objetiva fazer uma análise do que pode ser feito para o acurado diagnóstico e correção de manifestações patológicas mais recorrentes em edifícios históricos. Para delimitar o estudo, foram escolhidas quatro 
fachadas históricas de um conjunto urbano de importância ímpar para o município de Florianópolis. Com base na análise dos bancos de dados sobre patologia das construções, patrimônio material e correções de manifestações patológicas, o presente estudo discorre sobre a historicidade de tais edifícios, apresentando um mapeamento das principais degradações encontradas em suas fachadas frontais.

Cabe então aos engenheiros civis o aprimoramento técnico, por se tratar de uma área de extrema importância, não só para fortalecer com excelência o ramo de atuação dentro da construção civil, mas principalmente para a manutenção do patrimônio histórico nacional, que corre risco de extinção caso não sejam vistos com a dignidade e importância que tem para o país e para a sociedade.

\section{FUNDAMENTAÇÃO TEÓRICA}

A seguir são apresentadas as bases bibliográficas que sustentam os objetivos desta pesquisa. Estão subdividas em cinco partes, a saber: Patrimônio histórico cultural; Patologia das construções; Manifestações patológicas em patrimônio histórico; Manifestações patológicas em fachadas e Técnicas de inspeção visual. Optou-se por aprofundar esses elementos, uma vez que são necessários conhecimentos técnicos dessas subáreas de forma a garantir que a pesquisa tenha solidez ao que se propõe a estudar.

\subsection{Patrimônio Histórico e Cultural}

O conceito denominado "Patrimônio Cultural" está compreendido como uma reunião de bens para o interesse da preservação memorial da sociedade e envolve nosso patrimônio artístico, histórico, arquitetônico, acadêmico e museológico. Comumente pode envolver outras áreas não citadas, desde que contemple as expressões e os conhecimentos técnicos associados aos conjuntos que o associam, como objetos e lugares. Pode também definir um único individuo, desde que esse tenha importância frente ao grupo que pertence. Os patrimônios determinam a historicidade cultural, realizados pelos grupos sociais, que estudam o modo de vida humano em outras esferas temporais (POLISSENI, 2011).

Segundo IPUF-SEPHAN (2017) a cidade de Florianópolis tem se destacado no cenário turístico. Portanto, é de extrema importância que os elementos tradicionais e históricos da cidade estejam dentro dos parâmetros de preservação para que se possa passar para a população um pouco daquilo que constituiu a trajetória histórica da Ilha. Tem como referência principal o conjunto urbano representado pela Praça XV de Novembro e ruas adjacentes, o centro histórico, local onde se iniciou o povoamento e é até hoje o centro funcional da cidade (VEIGA, 2008).

\subsection{Patologia das Construções}

Assim como os humanos, os edifícios também estão sujeitos a doenças que podem afetar suas vidas úteis. A vulnerabilidade que ambos estão expostos podem levar à diversas consequências patológicas. Por isso, o estudo dessas doenças na medicina e na engenharia é denominado Patologia, mas na engenharia usa-se o termo "Patologias das Edificações", que objetiva estudar as origens, ocorrências, manifestações, causas e consequências que afetam os edifícios (VIEIRA, 2016). Portanto, a Patologia das Edificações é a área da Engenharia que estuda as formas, origens, causas e consequências das anomalias e das manifestações degradatórias (SOUZA, RIPPER, 1998).

\subsubsection{Origem das Manifestações Patológicas}

Os processos patológicos podem ter origens decorrentes em uma ou mais etapas do processo construtivo de uma edificação, as quais são divididas em três básicas denominadas: Concepção (fase de projeto); Execução (fase de construção) e Utilização (fase de utilização e manutenção). Destaca-se as fases de manutenção e utilização, em que aparece em relevância o desgaste natural das edificações como, por exemplo, o desgaste dos revestimentos em fachadas, as incrustações, as corrosões e outras pragas naturais que levam ao deterioramento das estruturas (AZEVEDO, 2011). Além da classificação em função da etapa, as manifestações patológicas podem ter origens resultantes de ações que podem ser de caráter físico, químico ou mecânico, englobando, por exemplo, chuvas dirigidas e intempéries (OLIVARI, 2003).

\subsubsection{Principais Sintomas Patológicos}

A maioria das manifestações patológicas podem ser estudadas apenas com a observação. Pelas determinantes encontradas, pode-se definir qual suas causas e sintomas, iniciando-se o sistema de tratamento após o devido e correto diagnóstico. Normalmente, os sintomas mais recorrentes em edificações são o esmagamento do concreto, a carbonatação, corrosões, 
fissuras e trincas. Também podem aparecer desagregações nos concretos e percolação de água, ocasionando manchas, trincas e descolamento de revestimentos (OLIVARI, 2003).

\subsection{Manifestações Patológicas em Patrimônio Histórico}

As edificações históricas, se não forem preservadas, são mais vulneráveis por diversos motivos, como já relatados anteriormente. Um desses motivos envolve o material utilizado na construção, que também contribui de forma muito significativa para o surgimento das manifestações patológicas (SOUZA, 1998).

Destacam-se neste cenário as infiltrações, os bolores e as fissuras. Também é recorrente observar o deslocamento de revestimentos e o desgaste das esquadrias e dos aparelhos hidrossanitários. As fissuras podem ser denominadas como aberturas que atingem a superfície das estruturas, e efetivam-se como uma causa para que agentes externos agridam as mesmas. Os deslocamentos de revestimento possuem como principal causa a umidade, que sem a correta impermeabilização possibilita que a água percole para dentro das alvenarias (CECHINEL et al., 2007).

Quando se trata de manifestações patológicas em edifícios históricos é válido ressaltar a importância do mapeamento dessas manifestações evidentes, para que se possa ter um memorial, de forma a preservá-los, mantendo sua fundamental base de ser patrimonial, contar a história e manter as tradições dos bens móveis e material dos mesmos (MOREIRA, 2006).

\subsection{Manifestações Patológicas em Fachadas}

Conforme já mencionado, as manifestações patológicas no cenário histórico patrimonial é de suma importância, uma vez que permite perpetuar a historicidade do país por várias gerações e, portanto, tem como característica evidenciar os cenários urbanos da forma mais similar possível com sua construção original. O passar dos anos deteriora muitas das obras materiais, principalmente as fachadas, e deve-se manter a qualidade das mesmas.

Logo, as manifestações patológicas em fachadas é um dos problemas mais comuns e preocupantes na construção civil, com o crescimento desordenado das cidades e de uma mão de obra desqualificada e escassa, esses fatores vêm agravando gradativamente, comprometendo a imagem da Engenharia e a integridade das construções (FREITAS et al, 2013).

\subsection{Técnicas de Inspeção Visual}

A avaliação de estruturas envolve uma mistura dos conhecimentos técnicos com o aprimoramento prático que a profissão exige, o que muitas vezes traz dificuldades para identificar e quantificar os elementos envolvidos nas manutenções das edificações.

Neste cenário, podem ser utilizados técnicas de inspeção não destrutivas. A técnica não destrutiva para inspeção das avaliações é utilizada para identificar as propriedades físicas e mecânicas dos materiais sem alterar suas capacidades de uso final. Após essa etapa, usa-se as informações para decidir as aplicações apropriadas para a execução, o que tem trazido contribuições significativas para a correta detecção das manifestações patológicas das edificações (BRITO, 2013).

\section{METODOLOGIA}

Para efetivar os objetivos acima citados, estabeleceu-se uma sequência de etapas metodológicas. A primeira determinou um levantamento bibliográfico, que compreendeu trabalhos teóricos desenvolvidos nos campos do conhecimento pertinentes às manifestações patológicas e mais especificamente em edificações históricas, como os conceitos de manifestações patológicas, edificações históricas e manifestações patológicas em edificações históricas.

Em um segundo momento foi realizada uma análise qualitativa do objeto de estudo desta pesquisa. Para isso, foi realizada uma anamnese do caso, a partir de uma síntese histórica permeando desde o tombamento do agrupamento histórico até sua classificação quanto à categoria de preservação; uma pesquisa e identificação da tipologia arquitetônica que compõem os edifícios e um reconhecimento geográfico e ambiental da região onde está inserido o objeto de estudo desta pesquisa. Visitas presenciais contribuíram com a observação sistemática da anamnese, objetivando o mapeamento das manifestações patológicas existentes nas fachadas dos edifícios históricos escolhidos, pertencentes ao conjunto urbano da Praça XV de Novembro. A coleta de dados foi acompanhada de registros fotográficos e conversas com responsáveis no local, o que favoreceu um melhor diagnóstico. 
A partir desses procedimentos obteve-se um pré-diagnóstico das manifestações patológicas, individualmente. Com a tabulação dos dados constitui-se o diagnóstico da situação, que determinou a recorrência das anomalias identificadas nos objetos em estudo. Elaborou-se, portanto, a Definição de Conduta, a partir de protocolos para o tratamento delas, em consonância com o referencial teórico deste estudo e a partir da coleta de dados do histórico das manutenções já realizadas nos edifícios. Determinou-se nesta etapa as causas, mecanismos de ocorrência e tratamentos.

\section{RESULTADOS}

A discussão dos resultados está dividida em cinco itens iniciais, contemplando uma síntese histórica do objeto de estudo, a tipologia arquitetônica, a localização geográfica, as características ambientais da região do estudo e as solicitações e intervenções registradas. Após essa análise de contextualização anteriormente citada, a discussão das manifestações patológicas diagnosticadas culmina em um diagnóstico da situação, que comtempla as manifestações patológicas apontadas como recorrentes entre as fachadas do estudo. Em seguida, serão apresentados os protocolos de tratamento dessas recursivas manifestações, citadas posteriormente e individualmente no item 4.11 deste capítulo.

\subsection{Síntese Histórica}

O conjunto arquitetônico da Praça XV de Novembro, edificado nos séculos XVIII e XIX, possui grande relevância para a história do município de Florianópolis. A cidade tinha como núcleo principal a Igreja Matriz, a Câmara e Cadeia, o Mercado e o Palácio do Governo. Dentro deste eixo central, as habitações foram edificadas, sendo estas, casas de um só pavimento ou sobrados de abastados comerciantes e funcionários do governo dos séculos XVIII e XIX.

Pelo seu reconhecimento histórico, os sobrados ao redor da Praça XV de Novembro são patrimônio municipal e protegidos, primeiramente, pelo Decreto $\mathrm{n}^{\circ} 22$ de 29 de fevereiro de 1980. Posteriormente, o tombamento do agrupamento histórico é reforçado pelo Decreto $\mathrm{n}^{\circ} 270 / 86$, que identifica o conjunto como o primeiro dentro dos conjuntos municipais. A classificação deste complexo, quanto à categoria de preservação, é estabelecida com o Decreto $n^{\circ} 521 / 89$, sendo eles considerados como P2. A área de interesse desse estudo contemplou as fachadas frontais dos edifícios históricos números 15, 16, 17 e 18, apresentados abaixo na Figura 1.

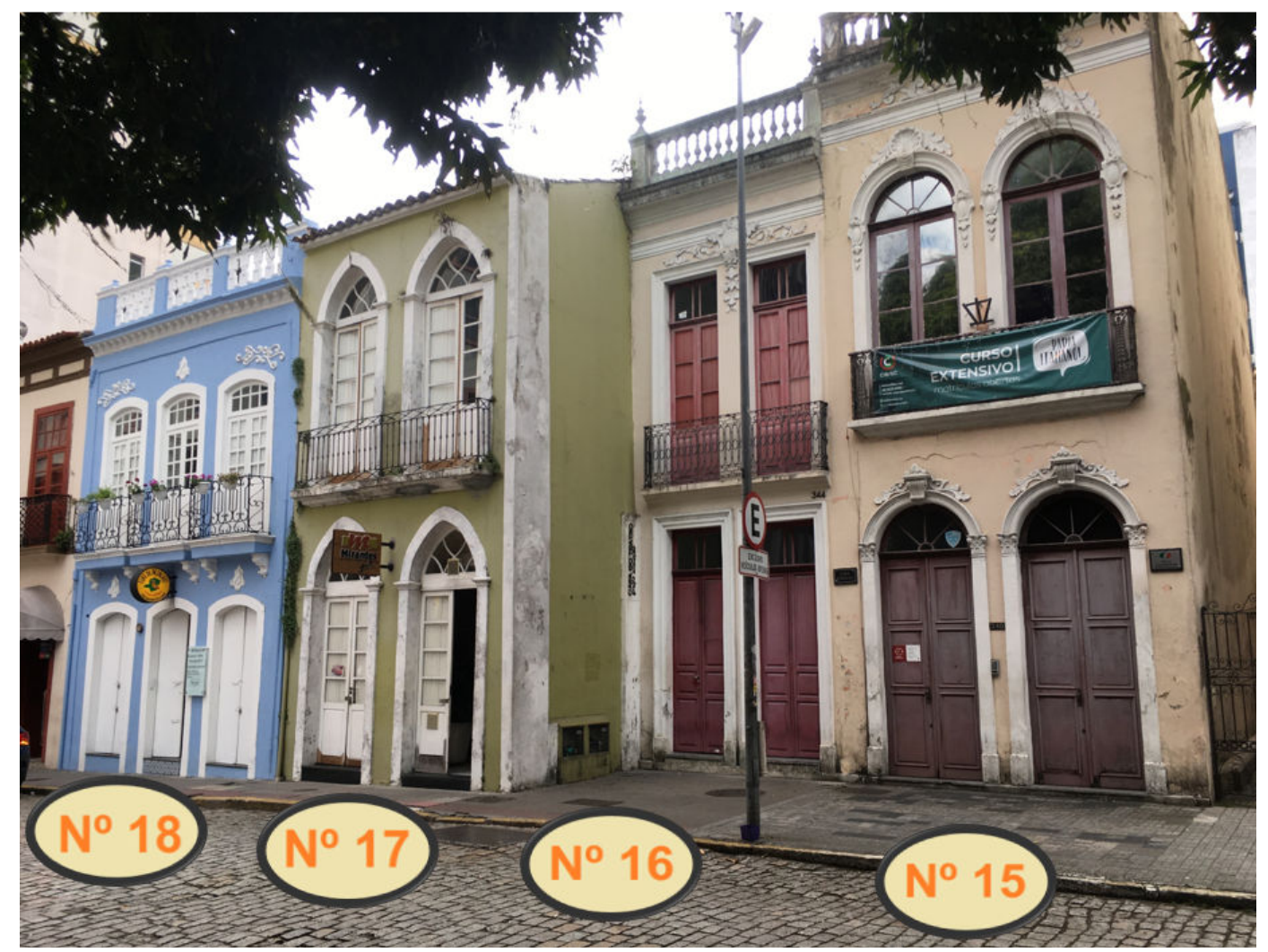

Figura 1: Conjunto arquitetônico objeto de estudo. 


\subsection{Tipologia Arquitetônica}

O conjunto arquitetônico objeto deste estudo é formado por quatro sobrados oitocentistas de características lusobrasileiras. Seu sistema estrutural, segundo informações coletadas junto ao SEPHAN, é composto por alicerces de alvenaria de pedra e barro, e paredes autoportantes que recebem os carregamentos da cobertura e os transmitem para a fundação. Internamente as paredes são em estuque e externamente em alvenaria rejuntada com argamassa à base de cal, e, possivelmente, ainda de acordo com SEPHAN (2019), com adição de óleo de baleia.

Exibem rica ornamentação com frisos e adornos de acabamento em argamassa. As sacadas possuem gradis em ferro e são sustentadas por balcões de alvenaria acabada em argamassa, elemento arquitetônico característico da época. Percebe-se uma padronização estética ao serem construídas sobre os limites laterais dos terrenos, um traço peculiar da arquitetura e da relação que as prende ao tipo de lote em que estão implantadas, colonial. Esse, cujas características envolvem dimensões frontais reduzidas e com grande profundidade, fazem com que o conjunto apresente uma composição volumétrica formada de longos blocos, fachadas frontais estreitas e espaços livres apenas nos fundos dos lotes.

\subsection{Localização Geográfica}

O objeto de estudo se localiza no conjunto urbano da praça XV de Novembro, no centro de Florianópolis. A praça é contornada por edifícios históricos e seu entorno é chamado pelo nome dado a ela, tendo em alguns trechos denominações mais recentes, como no caso dos edifícios 15 a 18, que se localizam na chamada Rua dos Ilhéus.

\subsection{Características Ambientais da Região do Estudo}

A área de estudo inicialmente se localizava a 250 metros do mar. No começo da década de 70 foi realizado um aterro estendendo a borda urbana e distando a orla para aproximados 700 metros do conjunto arquitetônico. Em ambos os casos se tem um alto índice de agressividade marinha, e presença de maresia, o que acaba por criar um ambiente mais nocivo aos componentes da edificação. Os elementos de fachada de maior suscetibilidade à corrosão, acabam apresentando maiores índices de deterioração, como os gradis da sacada e ferragens das esquadrias.

Como a região é constantemente atingida por chuvas, muitas vezes de alta intensidade, principalmente no verão, a área também sofre com alto índice de umidade. Com relação aos raios solares, eles atingem as fachadas frontais somente na parte da tarde (sol poente). Ainda assim, pela presença de frondosas árvores que compõem a praça, este sol fica reduzido à aproximadamente duas ou três horas/dia, cenário este que permite um baixo índice de insolação. E com relação aos ventos, as fachadas em estudo sofrem mais desgaste quando se trata de ventos provenientes do oeste e sul.

Sobre o discorrido neste item, destaca-se que a insuficiência de insolação nas fachadas frontais à praça e o alto índice de umidade na região são passíveis de maior cuidado, uma vez que favorecem o aparecimento de manifestações patológicas associadas à presença de manchas de umidade e proliferação de microflora.

\subsection{Solicitações e Intervenções Registradas}

A edificação de número 15 foi um casarão que pertenceu ao Governo do Estado desde 1985 e foi cedido ao Círculo ÍtaloBrasileiro (CIB) em 1999, que o reformou completamente em 2000 após um Incêndio que afetou a parte interna do edifício em 1994.

Com relação ao edifício número 16, no ano de 1986 o mesmo foi cedido também em caráter de comodato pelo governo ao Grupo de Teatro Armação, que foi ao longo do tempo adaptando a edificação para as necessidades do teatro. Em 1999, em decorrência da total precarização do imóvel, a companhia de teatro realizou uma série de espetáculos com o objetivo de arrecadar fundos para a execução emergencial de restauros do espaço. Com o dinheiro arrecado ao longo de vários anos, no ano de 2010 foi realizada uma reforma objetivando sanar as degradações ali presentes.

Sobre as edificações 17 e 18, pertencentes ao mesmo proprietário, que ao longo dos anos sublocava-as a diferentes áreas de comércio. Nesses períodos, foram abertas diversas consultas de viabilidade para reformas e ampliações (1988, 1990 e 1992), muitas vezes para ambos os prédios. Mesmo sem resposta da viabilidade, algumas reformas foram feitas de forma clandestina, o que se evidencia pelas solicitações do IPUF para que os departamentos de fiscalização embargassem o andamento das obras, como o registro localizado e datado de 1992. 
Um dos registros localizados traz um protocolo para pedido de aprovação de projeto de restauro em 1999. Porém, também localizou-se um embargo por obras clandestinas no ano de 2000. A mesma situação se repete na década seguinte, com novas notificações de embargo e um pedido vistoria no ano de 2009, sob a justificada de um destacamento do emboço do balcão de sustentação da sacada, deixando as ferragens a mostra, o que levava perigo aos transeuntes da região.

Neste mesmo ano foi protocolado um projeto de restauro e nenhuma nova informação posterior foi localizada junto ao Sephan. Em visita técnica ao local e conversa com o locatário do edifício 18, obteve-se a informação de que o imóvel passou por uma reforma integral da fachada a menos de seis meses. Essa contemplou a limpeza, correção de vesículas, empolamento do reboco com pulverulência e bolor junto à base.

\subsection{Diagnóstico das edificações avaliadas}

A edificação número 15 está locada na extrema direita do conjunto arquitetônico em estudo e sua fachada frontal possui de testada 4,74 metros. Após análise foram encontradas as seguintes manifestações patológicas: bolor e microflora junto à base; vesículas e degradações generalizadas; deterioração da madeira das esquadrias; vegetação parasitária; descolamento com empolamento e pulverulência; fissura diagonal nos vértices das aberturas; fissura vertical e degradação; fissura horizontal e desplacamento do reboco; sujidades (manchas escuras) e destacamento da camada de pintura.

A edificação número 16, por sua vez, está locada entre os edifícios números 15 e 17 e sua fachada frontal possui de testada 3,65 metros. Após análise foram encontradas as seguintes manifestações patológicas: Bolor e microflora junto à base; Vesículas e degradações generalizadas; Deterioração da madeira das esquadrias; Vegetação parasitária; Descolamento com empolamento e pulverulência; Fissura diagonal nos vértices das aberturas e Sujidades (manchas escuras). Neste caso estão presentes sete manifestações encontradas, localizadas na base da edificação, nas platibandas de coroamento e nas laterais próximas às esquadrias do térreo. Não foram identificados desplacamentos de reboco abaixo da sacada. Em relação às fissuras, notou-se a presença apenas de fissuras diagonais nos vértices das aberturas e o destacamento da camada de pintura aparece apenas na edificação anterior.

Já a edificação número 17 está locada entre os edifícios números 16 e 18 e sua fachada frontal possui de testada 5,35 metros. Após análise foram encontradas as seguintes manifestações patológicas: Bolor e microflora junto à base; Vesículas e degradações generalizadas; Deterioração da madeira das esquadrias; Vegetação parasitária; Descolamento com empolamento e pulverulência; Fissura diagonal nos vértices das aberturas e Fissura vertical e degradação. Com relação à localização das manifestações patológicas, neste edifício elas se localizam na base da edificação e nas laterais próximas às esquadrias do térreo, como ocorre nas anteriores. O que vale destacar é que nesse caso também surgem nas laterais próximas às esquadrias do segundo pavimento. Com relação à vegetação parasitária, essa pode ser encontrada distribuídas ao longo de toda a fachada, diferentemente das anteriores que eram localizadas apenas nas proximidades da platibanda de coroamento.

Por fim, a edificação número 18 está locada na extrema esquerda do conjunto arquitetônico em estudo e sua fachada frontal possui de testada 6,70 metros. Após análise foram encontradas as seguintes manifestações patológicas: Bolor e microflora junto à base; Vesículas e degradações generalizadas; Deterioração da madeira das esquadrias e Eflorescência. Vale destacar que esta edificação teve uma reforma integral de sua fachada a menos de seis meses, é o que menos traz manifestações patológicas, mas com relação às vesículas é a que as apresenta em pior grau, ocasionada possivelmente por uma pintura sobre superfície úmida. Ressalta-se que o item que aparece e é recorrente nas outras fachadas é a deterioração da madeira das esquadrias junto à base, que devido a condições de umidade ascensional, acaba por ser uma manifestação facilmente ressurgente.

Devido a umidade constante ao longo da fachada junto à base, o bolor e a microflora são sintomas que já podem ser visíveis e que em pouco tempo se tornarão uma anomalia de grau avançado. A eflorescência foi encontrada apenas nesta fachada também devido a superfície úmida e identificada a partir das manchas esbranquiçadas ao longo de toda lateral esquerda. Sua causa possivelmente é decorrente da presença de sais solúveis na alvenaria.

As Figuras 2 e 3, apresentadas a seguir, trazem o mapeamento individual das manifestações patológicas diagnosticadas nos edíficios em estudo, legendadas de acordo com as marcações de cada uma das manifestações encontradas: 


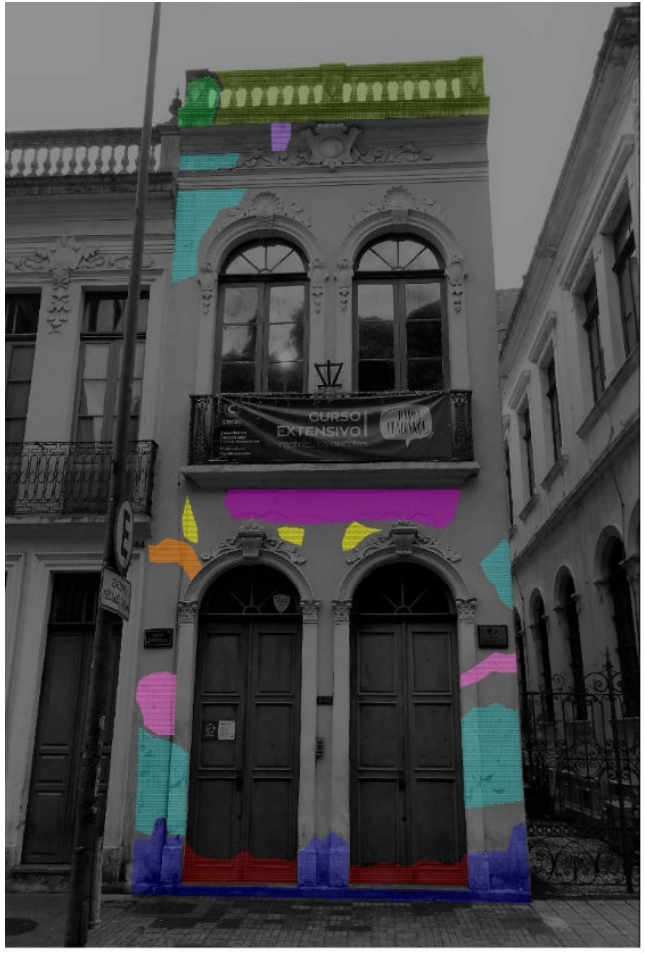

Bolor e microflora

Vesículas

Deterioração madeira

Vegetação parasitária Empolamento

Fissura diagonal
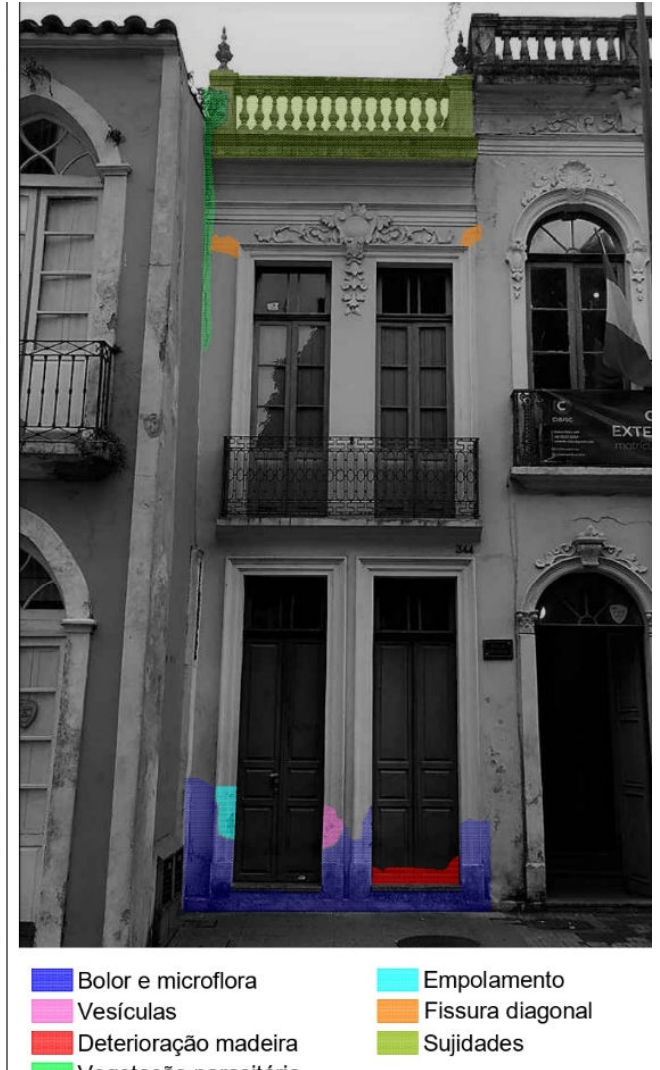

Figura 2: Mapeamento manifestações patológicas nas edificações 15 e 16.

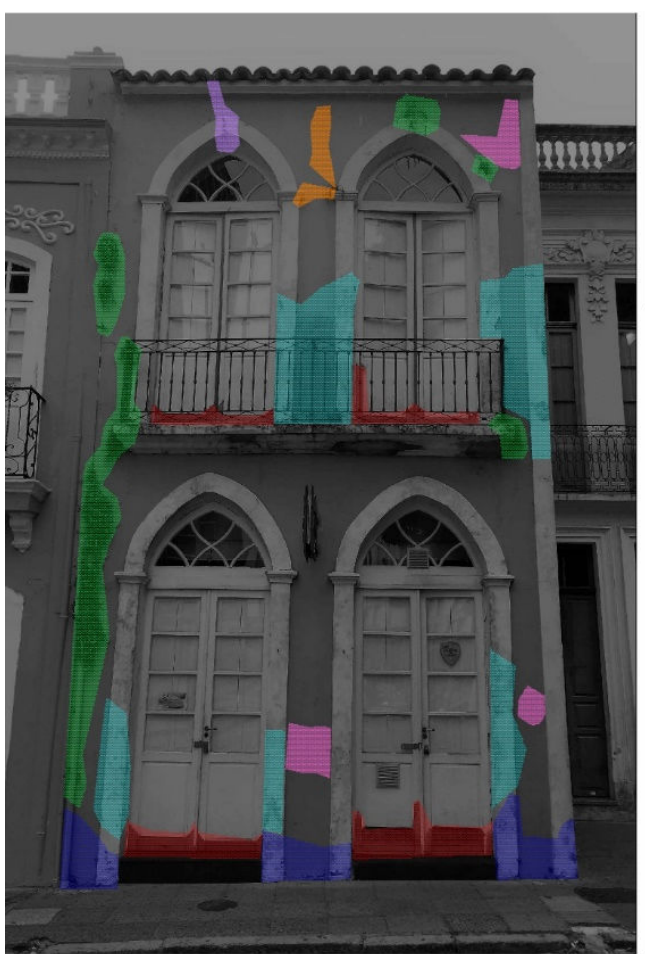

Bolor e microflora Vesículas

Deterioração madeira Vegetação parasitária

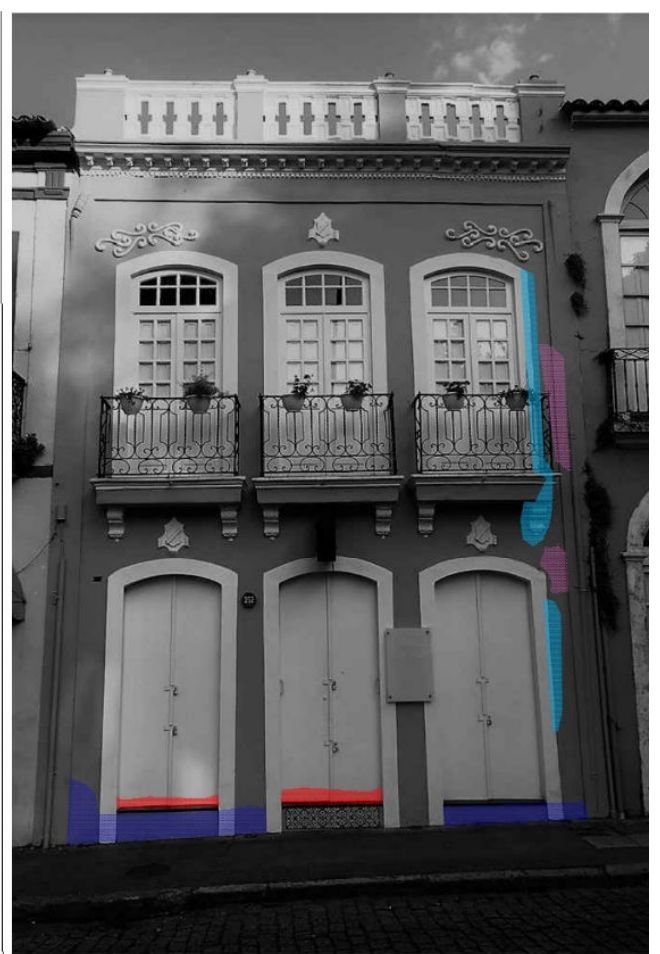

Bolor e microflora

Vesículas

Deterioração madeira Fissura diagonal Fissura vertical

Figura 3: Mapeamento manifestações patológicas nas edificações 17 e 18. 


\subsection{Diagnóstico da Situação}

Após as análises individuais dos edifícios estudados dentro do conjunto arquitetônico, as manifestações patológicas mais recorrentes são: Bolor e microflora junto à base; Vesículas e degradações generalizadas; Deterioração da madeira (esquadrias); Vegetação parasitária; Descolamento com empolamento e pulverulência e Fissura diagonal nos vértices das aberturas. Entende-se por essas, as que aparecem identificadas em todas as fachadas, bem como também as manifestações patológicas que aparecem em pelo menos três fachadas, uma vez que se considera, que por estarem presentes na maioria dos objetos do estudo, podem ser consideradas recorrentes e são plausíveis de maior atenção no tangente ao efetivo diagnóstico e correções.

A Figura 04 a seguir representa um gráfico com a porcentagem de incidência das manifestações patológicas recorrentes e descritas anteriormente. São mostradas manifestações com prevalência de $75 \%$ e $100 \%$, ou seja que aparecem em pelo menos três edifícios.

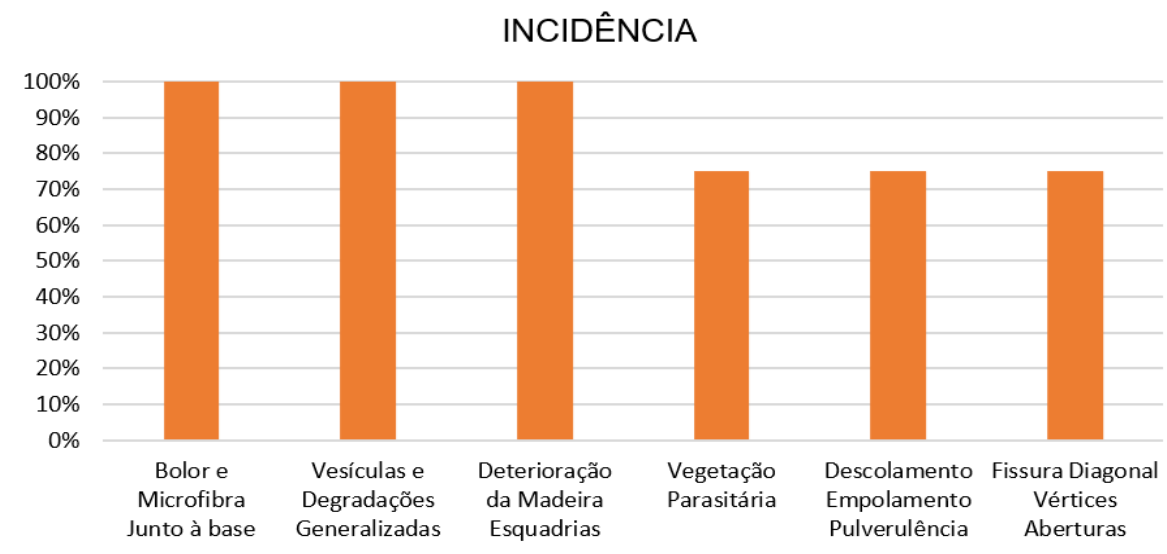

Figura 4: Gráfico de Incidência.

\subsection{Protocolo de Tratamento: Definição de Conduta}

Identificadas as manifestações patológicas mais recorrentes, apresentam-se os protocolos de tratamentos que se referem à uma compilação de passos a serem usados para o tratamento das anomalias. Eles seguem rigorosos processos indicados pela Engenharia Civil de forma a corrigir e minimizar fatores relacionados ao tratamento dos itens a seguir.

Para melhor compreensão da definição de conduta, é descrita a manifestação (sintoma observado), as prováveis causas, os mecanismos de ocorrência e o tratamento sugerido.

\subsubsection{Bolor e microflora junto à base}

O bolor manifesta-se na forma de manchas esverdeadas ou escurecidas, com consequente degradação de revestimento. Tem como possíveis causas a presença de altos índices de umidade ascensional, umidade ascendente proveniente do solo (falhas no sistema de impermeabilização das fundações ou inexistência do mesmo) e baixa exposição solar. Nota-se a presença de microflora como agente responsável pelo processo biodegenerativo.

Sendo assim, pode-se definir os mecanismos de ocorrência pela proliferação dos microrganismos que causam o bolor visível a olho nu a partir da observação de manchas escurecidas com cores em tonalidade de preto, verde ou marrom. Quando se tem poeira aumenta-se a proliferação uma vez que servem como nutriente aos microrganismos.

Como tratamento, tem-se a necessidade de identificar a fonte de umidade que está sustentando o desenvolvimento da referida manifestação patológica. Sendo ela a umidade ascensional, o local deve ser limpo, através de processos de lavagem com jatos de alta pressão em solução de hipoclorito de sódio $12 \%$, deixando o produto agir na superfície por cerca de 20 minutos. Esse procedimento reduzirá ou eliminará por completo os microrganismos patogênicos presentes. Passado o tempo de ação do produto, a área deverá ser lavada com água abundante de modo a eliminar os vestígios de cloro. As regiões da superfície que, devido à perda de coesão do material, apresentarem desagregação do revestimento deverão ser raspadas até que se encontre a camada sã. Concluída a etapa de remoção do material em mau estado, as 
superfícies expostas e as zonas que estarão em contato com o novo revestimento deverão ser limpas com o auxílio de uma brocha ou escova, aplicando-se em seguida fungicidas de modo a inibir os ataques biológicos. Em seguida, inicia-se a reexecução do revestimento argamassado à base de cal, colocando inicialmente uma capa de material leve, aplicando-o como se fosse uma pintura que preencherá os interstícios criando uma superfície de aderência para receber o novo material. Com a superfície completamente seca e limpa aplicar as camadas de pintura utilizando tintas minerais à base de cal e contendo aditivos fungicidas.

A eficácia destes tratamentos depende dos métodos e dos produtos empregados, contudo por se tratar de umidade ascensional vale destacar que o crescimento destes micro-organismos causadores do bolor e microflora retornará, inevitavelmente, visto que neste cenário não é possível se obter um tratamento definitivo.

\subsubsection{Vesículas e degradações generalizadas}

Tais problemas manifestam-se pela presença de bolhas com umidade e empolamento de pintura com degradações esbranquiçadas na parte interna. São provocados por diminuição do tempo da hidratação da cal e aplicação antecipada de tinta em superfícies úmidas. Tem-se que quando hidratada de forma atrasada, a cal provoca o estufamento do revestimento e, assim, se formam vesículas esbranquiçadas. Com umidade, a mesma pode atingir a parte interna da vesícula com a ocorrência de bolhas.

Como tratamento sugere-se a remoção de todo o revestimento afetado. A superfície deverá ser raspada até que se encontre a camada sã e concluída a etapa de remoção do material que apresenta a vesícula, as superfícies expostas e as zonas que estarão em contato com o novo revestimento deverão ser limpas com o auxílio de uma brocha ou escova e umedecidas. Em seguida, inicia-se a reexecução do revestimento argamassado à base de cal, colocando inicialmente uma capa de material leve, aplicando-o como se fosse uma pintura, que preencherá os interstícios criando uma superfície de aderência para receber o novo material. Com a superfície completamente seca e limpa aplica-se as camadas de pintura utilizando tintas minerais à base de cal.

Vale destacar que quando os mecanismos de ocorrência estiverem associados à presença de umidade, a origem da mesma deverá ser identificada e devidamente sanada, visto que a eficácia destes tratamentos depende dos métodos e dos produtos empregados, contudo se os mecanismos de ocorrência persistirem, inevitavelmente, a anomalia retornará.

\subsubsection{Deterioração da madeira - esquadrias}

Neste caso, tem-se o desgaste das madeiras das esquadrias, por fatores biodeterioradores, devido à presença de altos índices de umidade associada a uma insolação insuficiente. O mecanismo de ocorrência presente é explicado pelo ataque dos agentes biodeterioradores à madeira e colaboram para a perda das características funcionais e estéticas que irão evoluir para a degradação do material. Reforça-se que neste caso o estudo da madeira se dá em caráter estético.

O tratamento inicia-se, também, pela remoção dos trechos deteriorados da madeira da esquadria que apresentarem grandes falhas, substituindo-os em processos de emendas. Inicialmente, remove-se cuidadosamente com o auxílio de um formão, todo o material degradado e imuniza-se a parte interna agora exposta, para em seguida aplicar o novo pedaço de madeira, atentando-se em utilizar o mesmo tipo ou a madeira mais semelhante possível. A fixação se faz com cola específica epoxídica e enquanto não estiver completamente seca e aderida é necessário deixar a emenda presa por grampos para garantir a correta fixação.

Pequenas falhas serão reparadas em procedimentos de enxertos, que deverão ser feitos a partir de uma mistura entre cola epoxídica e pó de serra fino, sem ser de uma madeira mais dura ou em tom diferente da madeira original. Tomando sempre o cuidado de deixar o preenchimento sobressalente para que seja possível realizar o acabamento com etapas de raspagem utilizando lixas específicas para madeira. Concluídas as etapas de reparo, e estando a superfície da madeira devidamente seca, limpa e regularizada, deverão ser imunizadas com fungicidas e após a secagem do mesmo aplicadas camadas de pintura com tintas à óleo ou esmalte sintético. Nas emendas, peças novas, deverão ser aplicadas fundo nivelador de madeira antes da pintura.

Vale destacar também que quando necessário, poderão ser utilizados reforços metálicos, bem como a eficácia destes tratamentos depende dos métodos e dos produtos empregados, contudo a recorrência da manifestação patológica, está diretamente associada a persistirem ou não as condições ambientais que ocasionaram seu surgimento e desenvolvimento. 


\subsubsection{Vegetação Parasitária}

A vegetação parasitária é diagnosticada pela observação do brotamento de vegetação e superfície apresentando proliferação de microrganismos. É decorrente do excesso de calor e umidade que colaboram para o surgimento e evolução de vegetação. Neste problema, observa-se que a umidade permite o surgimento de vegetação, que com a influência solar se desenvolvem, causando aumento de áreas com musgos e bolores e que acabam por se transformar em vegetação aparente que podem afetar toda estrutura e trazer novas manifestações patológicas. Fatores orgânicos como fezes de aves servem como adubo para o desenvolvimento das mesmas.

O tratamento consiste na retirada cuidadosa da vegetação, de modo que as raízes incrustadas no revestimento não o danifiquem ao esforço axial de arranque e em seguida deverá ser aplicado herbicidas sobre a região. Após essa etapa, o local deve ser limpo, através de processos de lavagem com jatos de alta pressão em solução de hipoclorito de sódio $12 \%$, deixando o produto agir na superfície por cerca de 20 minutos, esse procedimento reduzirá ou eliminará por completo as sujidades ou organismos renascentes da extração da vegetação existente. Passado o tempo de ação do produto, a área deverá ser lavada com água abundante de modo a eliminar os vestígios de cloro. Com a superfície completamente seca e limpa se refaz a camada de pintura utilizando tintas minerais à base de cal.

\subsubsection{Descolamento com empolamento e pulverulência}

O descolamento manifesta-se pelo surgimento de bolhas e desagregações da argamassa com pulverulência ao longo da estrutura. O reboco possui som cavo e tem desprendimentos estruturais com acúmulo de material quebradiço, esbranquiçado. Como causas prováveis citam-se o excesso de finos no agregado com traços ricos em aglomerantes e em cal com ausência de carbonatação e reboco aplicado em camada muito espessa. A umidade ascendente movimenta o fluxo da água a partir do solo acompanhada dos sais dissolvidos que após a evaporação formam depósitos salinos na superfície com consequente desprendimento do revestimento.

As regiões nas quais aparece tal anomalia devem ter sua remoção completa. Corta-se a área com anomalias evidentes até atingir a base da alvenaria em um corte esquadrejado. O material com baixa aderência então é removido com escovação de material de cerdas duras. As áreas em contato com o novo revestimento devem ser limpas com brochas e umidificadas. Após isso realizado, será feita a reexecução do revestimento, com aplicação de uma camada de emboço em argamassa de cal e areia grossa (traço 1:2 ou 2:5), que deve conter texturização com desempenadeira dentada, uma vez que irá facilitar a aderência do reboco de argamassa de cal e areia fina (traço 1:3). Com a superfície completamente seca e limpa aplicar as camadas de pintura utilizando tintas minerais à base de cal.

A eficácia destes tratamentos depende dos métodos e dos produtos empregados, contudo, pelo mecanismo de ocorrência se tratar principalmente de umidade ascendente, vale destacar que possivelmente o surgimento da anomalia retornará, visto que neste cenário não é possível se obter um tratamento definitivo. Em situações onde a ocorrência está relacionada à presença de umidade de infiltração, a origem da mesma deverá ser identificada e devidamente sanada.

\subsubsection{Fissura diagonal nos vértices de aberturas}

As fissuras que ocorrem a partir dos vértices das aberturas (esquadrias) tem como principal causa a ausência de estruturas de concreto para a correta absorção das tensões ou esforços superiores aos esperados para as vergas existentes. O excesso de peso em torno de aberturas causa fissuras nas paredes de alvenaria descontínuas quando submetidos a carregamentos de compressão com base em seus vértices.

Localizadas, as fissuras diagonais deverão ser seladas, iniciando esse trabalho com a limpeza da área e com escareamento que permitirá preencher os vazios existentes com argamassa de cal e areia de baixa espessura. Concluída a etapa de escareamento, as superfícies expostas e as zonas que estarão em contato com o novo revestimento deverão ser limpas com o auxílio de uma brocha ou escova, realizando-se na sequência um grampeamento da alvenaria executando furos e chumbando elementos metálicos de modo a absorver os esforços que estão gerando as fissuras. Em seguida, inicia-se a reexecução do revestimento argamassado à base de cal e sugere-se a adição de aditivos para tornar o revestimento final mais flexível. Com a superfície completamente seca e limpa, aplicar as camadas de pintura utilizando tintas minerais à base de cal ou tintas elastoméricas. 


\section{CONSIDERAÇÕES FINAIS}

A partir da exposição sintética dos itens que foram pesquisados, considera-se fundamental a preservação dos edificios históricos nacionais. Reitara-se a importância da Engenharia Civil nesse âmbito, uma vez que cabe aos profissionais da área as ações de identificação e mapeamento das manifestações patólogicas, bem como ser responsáveis pelas devidas correções que devem ser realizadas.

Constatou-se nesta pesquisa que as principais manifestações patólogicas encontradas no conjunto urbano histórico da Praca XV de Novembro, em Florianópolis foram: Bolor e microflora junto às bases; Vesículas e degradações generalizadas; Deterioração das madeiras (esquadrias); Vegetação parasitária; Descolamento com empolamento e pulverulência e Fissura diagonal (vértices das aberturas).

Vale mencionar que os resultados aqui apresentados fazem parte de um primeiro grupo de dados coletados pela autora principal, em seu Trabalho de Conclusão de Curso. Procurou-se respeitar os aspectos de reparo e restauro das edificações, valorizando sua importância histórica-cultural. Assim sendo, pode-se também ampliar essa linha de pesquisa, com análises de outros conjuntos urbanos em outras regiões do Brasil. E, inclusive, pode-se analisar qual a influência de aspectos geográficos, temporais, habitacionais e de ocupação, como possíveis agentes de desgaste dos edificios e das ocorrências de manifestações patólogicas nos mesmos. Vale ressaltar que são a partir de pesquisas deste caráter que se consegue fazer influência nos orgãos públicos, justicando a liberação de verbas e projetos para a restauração e preservação histórica do patrimônio nacional.

Ao que se propôs, a pesquisa obteve sucesso ao conseguir mapear e identificar as principais manifestações patológicas do conjunto estudado e, a partir disso, se realizou um manual que poderá ser utilizado pelos colegas de profissão que atuam na mesma linha de pesquisa.

\section{REFERÊNCIAS}

ARGAN, Giulio Carlo. História da arte como história da cidade. São Paulo: Martins Fontes,1995.

AZEVEDO. Minos Trocoli. et al. Concreto: Ciência e Tecnologia. São Paulo: Ibracon, 2011. 1902p, v.2.

BARBOSA, Maria Teresa Gomes (1); POLISSENI, Antônio Eduardo (2) \& TAVARES, Fabiana Mendes (3), Patologias de Edifícios Históricos Tombados, Rio de Janeiro, 2010

BAUER, L. A. F. Materiais de Construção. 5ed. Rio de Janeiro: Livros Técnicos e Científicos Ed., 2008. Volume 2.

BRITO, L. D. Técnicas não destrutivas (NDT) utilizadas nas inspeções para avaliações dos elementos estruturais de madeira da cobertura da "Igreja São Francisco" em Florianópolis, Brasil, In: IX Internacional Congresso on Pathology and Recovery Structures. João Pessoa, 2013.

CABRAL, Oswaldo. Nosso Senhora do Desterro. Florianópolis, 1979.

CARVAlHO, Ana Carla de. Convergências Contemporâneas nas Cidades Tombadas: A Ascensão Turística e o Tráfego na Cidade de Tiradentes-Mg. Dissertação de Mestrado. Belo Juiz de Fora: Universidade Federal de Juiz de Fora, 2013.

CECHINEL, B. M.; Mantelli, P.; Tonel, S.; Vieira, F. L. Infiltração em alvenaria: estudo de caso em edifício na grande Florianópolis. 2018

CINCOTTO, M. A. Patologia das argamassas de revestimento: análise e recomendações. In. Tecnologia das Edificações. São Paulo: Pini/IPT, 1988.

FREITAS, A. H. C.; FRANÇA, P. M.; FRANÇA, T. M. PATOLOGIA DE FACHADAS. Artigo Revista Pensar, vol 1, n 2, julho 2013. 
FREITAS, J. G.DE; CARASEK, H.; CASCUDO. A utilização de termografia infravermelha para avaliação de fissuras em fachadas com revestimento de argamassa e pintura. Ambiente Construído, Porto Alegre, v. 14, n. 1, p. 57-73, jan./mar. 2014.

GONÇALVES, E. A. B. Estudo de Patologias e suas Causas nas Estruturas de Concreto Armado de Obras de Edificações. 1. ed. Rio de Janeiro: Universidade Federal do Rio de Janeiro, 2015. 174 p.

LICHTENSTEIN, Norberto. Patologia das Construções. Boletim Técnico EPUSP nº, 1986.

MAIA, Felícia Assmar. Direito à memória: o patrimônio histórico, artístico e cultural e o poder econômico. Belém: Movendo Idéias, v8, n.13, jun 2003.

MOREIRA, Christian. Realcalinização de estruturas de concreto carbonatado com utilização de gel saturado de solução alcalina. Goiânia, 2006.

MOTTA, E. V.; GLEICE, P. J. P.; SILVA, D. A.; ROMAN, H. R. Caracterização de Argamassas de Edificações Históricas de Santa Catarina. VI Simpósio Brasileiro de Tecnologia de Argamassas - SBTA, Florianópolis, 2005.

NAPPI, Sérgio Castello Branco. Uma solução alternativa para prorrogação da vida útil dos rebocos com salinidade em edifícios históricos. Tese (Doutorado em Arquitetura e Urbanismo) - Universidade Federal de Santa Catarina, Florianópolis, 2002.

OLIVARI, Giorgio. Patologia em Edificações. Defesa - trabalho de conclusão de curso, graduação em engenharia civil, dissertação. São Paulo: Universidade Anhembi Morumbi.2003. 95p.

OLIVEIRA, F. MATSUY, K. Mapeamento de danos do painel de azulejos do largo da memória, São Paulo/SP. João Pessoa: Anais do IX Congresso Internacional Sobre Patologia e Recuperação de Estruturas - CINPAR, 2013.11 p.

PATRÍCIO, F.J.S. Reabilitação de edifícios no Centro Histórico de Amarante Análise das casas da Portela e de Vasconcelos. Dissertação de Mestrado - Universidade Fernando Pessoa, Porto, 2013.

PERES, R. M.; GREVEN, H. A.; ZAMBRANO, L. G.; BONIN, L. C. Um Estudo de Caso sobre a Reconstituição de Traço de Argamassas Históricas. VI Simpósio Brasileiro de Tecnologia de Argamassas - SBTA, Florianópolis, 2005.

PEREZ, A. R. Umidade nas Edificações: recomendações para a prevenção da penetração de água pelas fachadas. In: Tecnologia de Edificações: $1^{a}$ parte. São Paulo: PINI, IPT-Divisão de Edificações, 1988. p. 571-574.

REGINATTO, G. M. P. Inspeção e diagnóstico de estruturas de cobertura de edificações históricas em Florianópolis, Santa Catarina, Cuiabá, 2004.

SHIRAKAWA, M.A.; MONTEIRO, A.B.B.; SELMO, S.M.S.; CINCOTTO, M.A. Identificação de fungos em revestimentos de argamassa com bolor evidente. Simpósio Brasileiro de Tecnologia de Argamassas. Goiânia, 1995.

SOUZA. M. Vicente Custódio e RIPPER. Thomaz. Patologia, Recuperação e Reforço de Estruturas de Concreto. São Paulo: PINI, 1998.

REICHERT, Sabrina. Análise das Manifestações Patológicas em Edificações Históricas: Um estudo de caso nas fachadas do conjunto urbano da Praça XV de Novembro de Florianópolis-SC. Trabalho de Conclusão de Curso (Graduação em Engenharia Civil). Faculdade Unisociesc. Florianópolis. 2019.

VEIGA, Eliane, Florianópolis Memória Urbana, Florianópolis, 2008.

VEIGA, M. Rosário e Carvalho, Fernanda. 2002. Argamassas de reboco para paredes de edifícios antigos: requisitos e características a respeitar. [autor do livro] Laboratório Nacional de Engenheira Civil. Cadernos Edifícios nº 2. Lisboa: LNEC, 2002. 